\title{
Research on System Analysis and Control Strategy of Electrical Brake in A Series- parallel Hybrid Electric Vehicle
}

\author{
Xiaoxia Sun, Chunming Shao, Guozhu Wang, Lining Yang, Xin Li, Yusong Yue \\ China North Vehicle Research Institute, Beijing, China
}

\begin{abstract}
For the sake of high-efficiency energy recycling and brake security for series-parallel hybrid electric vehicle, an integrated brake system with an electric consuming brake subsystem and advanced strategy is proposed. The specific structure of electric consuming brake subsystem is introduced. The brake processes in different brake conditions are analyzed. A brake control strategy relying on the brake condition is applied in the series-parallel hybrid electric vehicle. In view of the complexity and dynamic characteristics, a coupled whole vehicle model which combined the driveline model and the thermal management system model is proposed to study the energy flow and utilization in the different electrical brake processes. A simulation of the whole vehicle under an UDDS driving cycle is studied. According to the simulation result, the integrated brake system and control strategy are effective for the series-parallel hybrid electric vehicle. It not only can ensure the security of the vehicle driving and battery energy storage, but also can enhance the energy utilization and prolong the life of mechanical brake device in the brake process.
\end{abstract}

\section{Introduction}

As the global issues of energy scarcity and environmental pollution get more and more remarkable, the research of the hybrid electric vehicle, which has the advantages of both electric vehicles and traditional internal combustion vehicles, has become the hot point in the vehicle research field at present. The powertrain of hybrid electric vehicle is incredibly complex, with mechanical, electrical and thermal interactions between the internal combustion engine, gearboxes, electrical machines, power electronics, controlling systems and so on. The brake energy recycling is a typical characteristic of hybrid electric vehicle, which can affect both the security and energy saving of the whole vehicle.

Therefore, there are a lot of researches have been pursue $\mathrm{d}$ on the brake energy recycling, ranging from cooperative control[1-4] of regenerative brake and friction brake to the dynamic performance analysis in brake process[5-7]. However, the common trait of these existing hybrid electric vehicle brake control strategies is to use mechanical friction brake instead of electrical brake completely in the highintensity brake or high battery state of charge (SOC) and high battery voltage conditions in order to ensure the safety of the driving and charging. That results in a kind of waste of brake energy as well as reducing the working lifetime of the mechanical brake. In this paper, a unique integrated brake system with adaptive control strategy is applied to a seriesparallel hybrid electric vehicle. This brake system contains an electric consuming brake subsystem which can effectively protect the battery. With this subsystem, the electrical brake and electrical-mechanical combined brake can still be used safely in high battery SOC and high voltage conditions. According to that, the energy generating from the brake process can be fully utilized and the lifetime of the mechanical brake device can be prolonged. In view of the complexity and dynamic characteristics, an integrated simulation analysis method based on a mechanical-electricalthermal coupled simulation model is proposed to study the energy flow and utilization in the electrical brake process.

\section{Brake System Analysis}

\subsection{Brake schematic of Series-parallel hybrid electric vehicle}

Depending on the operating conditions and work processes, the electrical brake of the series-parallel hybrid electric vehicle can be divided into two forms, regenerative brake and electric consuming brake. In the regenerative brake process, the electricity generated from the brake process is used to charge the battery. The regenerative brake strength is affected by many factors, such as the maximum allowed working current of motor in generating mode, the maximum charging current and voltage of battery and so on. The electric consuming brake is applied in the high intensity brake process or continuous brake process. In these situations, the recycled electrical brake energy could not be fully absorbed because of the capability limitation of the energy storing components such as battery. Under this circumstance, the brake resistor belonged to the electric consuming brake subsystem should be applied to consume and transfer the surplus energy in order to assure the safety and reliability of vehicle. The schematic of electrical brake process and energy flow of this series-parallel hybrid electric vehicle are shown in Figure 1. According to the principles of optimum of energy conservation, the minimizing of the wear 
of mechanical brake components and the maximum protection of the battery, the brake priority can be defined in the following stages. The first brake stage is regenerative brake. The second one is regenerative brake combined with electric consuming brake. The third one is electricalmechanical combined brake. According to the vehicle operating state, the proper selection of electrical brake modes can greatly reduce the usage intensity and frequency of mechanical friction brake components and increase their working lifetime and operation reliability.

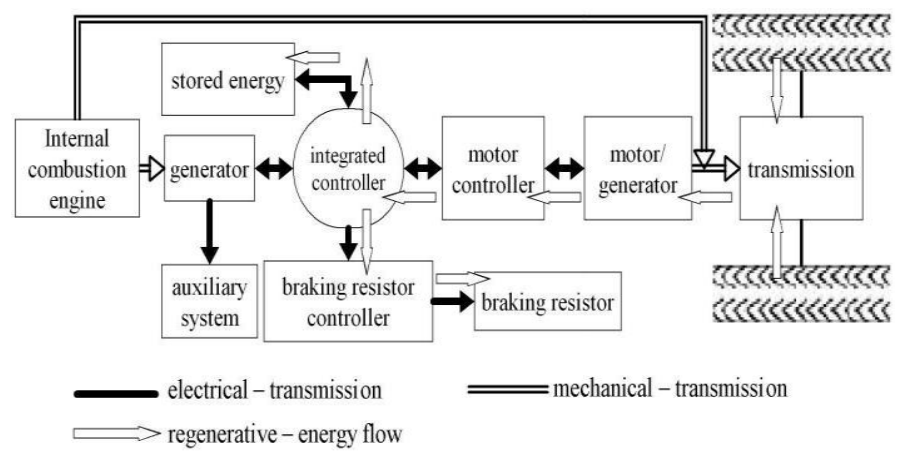

Figure 1. The schematic of the electrical brake of series-parallel hybrid electric vehicle.

\subsection{Structure of electric cosuming brake system}

Electric consuming brake system is a very important part in the electric brake system of series-parallel hybrid electric vehicle which plays a key role in the safety brake process. It contains brake resistor and energy consuming cooling subsystem. Electric consuming cooling subsystem is designed as part of the thermal management system. The type selection of brake resistor electric consuming cooling subsystem depends on the structure of brake resistor. At present, there are two universal cooling methods: air cooling and oil cooling. The electric consuming brake system with air cooling subsystem contains brake resistor, adjustable air flow door and cooling fan. The electric consuming brake system with oil cooling subsystem contains brake resistor, oil pump, brake resistor radiator and cooling fan. In this study, an electric consuming brake system with energy consuming oil cooling subsystem of a series-parallel hybrid electric vehicle is studied. Brake resistor is a key component in the energy consuming process, which is made up of brake resistor unit and brake resistor case. The resistor unit includes many resistor strips which arrange in series. The structure schematic of resistor unit is shown in Figure 2. The case of the brake resistor is made by aluminum, shown in Figure 3. The cooling oil is filled in the brake resistor case. The material of the resistor strip is the alloy of nickel and chromium. The material characteristic parameters can be seen in Table 1. According to the operating traits of the series-parallel hybrid electric vehicle, a distinct thermal management system with energy consuming brake system for the series-parallel hybrid electric vehicle is acquired.

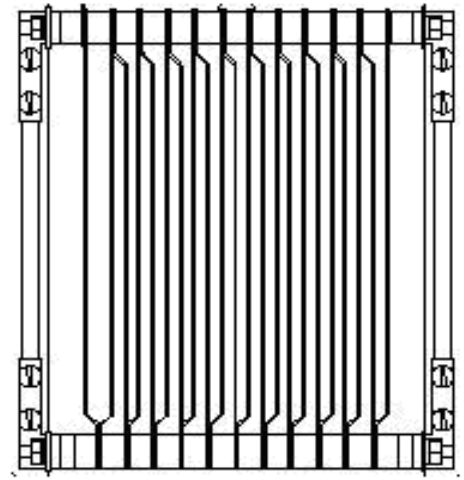

Figure 2. The schematic of the resistor unit

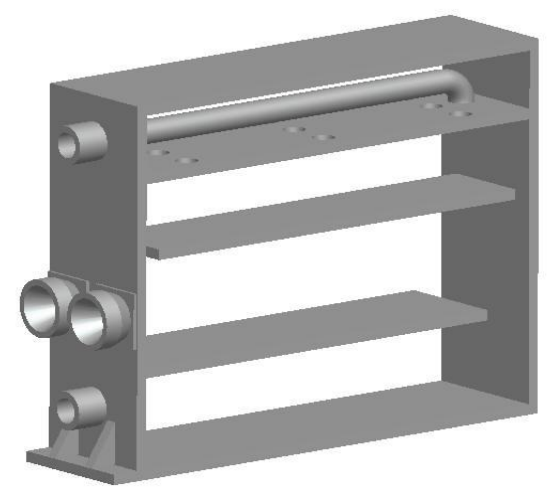

Figure 3. The structure of the brake resistor case

Table 1 Material Characteristic Parameters of the Alloy of Nikel and Chromium

\begin{tabular}{|c|c|c|c|c|}
\hline \multirow{2}{*}{ Parameters } & \multicolumn{4}{|c|}{ Cr20Ni80 } \\
\cline { 2 - 5 } & $\mathbf{3 0 0 K}$ & $\mathbf{4 0 0 K}$ & $\mathbf{6 0 0 K}$ & $\mathbf{8 0 0 K}$ \\
\hline Melting point[K] & 1672 & 1672 & 1672 & 1672 \\
\hline Density[kg/m $\left.{ }^{3}\right]$ & 7900 & 7900 & 7900 & 7900 \\
\hline $\begin{array}{c}\text { Specific heat } \\
\text { capacity[J/(kg.K)] }\end{array}$ & 420 & 480 & 525 & 545 \\
\hline $\begin{array}{c}\text { Thermal } \\
\text { conductivity[W/(m·K)] }\end{array}$ & 12 & 14 & 16 & 21 \\
\hline
\end{tabular}

When brake resistor operates, electricity flows away the resistor strips and generates heat. As the time going on, the temperature of resistor gradually increased as the electrical load increasing. Meanwhile resistor transfers the heat to the cooling oil by the oil circulation loop which dissipates the heat according to the brake resistor radiator. At any instant, the transient balance temperature of brake resistor depends on the combined effects of electricity or heat load, the heat dissipation ability of cooling oil and the structure and material character parameters of brake resistor. 


\subsection{Operation of electric cosuming brake}

Based on modular design method, the electric consuming cooling system related to the electric consuming brake subsystem is designed as part of thermal management system. The schematic of thermal management system under electric consuming brake is shown as Figure 2. The red parts in the picture are the main heat source components in the brake process. In this self-adaptive thermal management system, electric pump and electric fan which can be continuous speed adjusted are applied in light of the system flexible control. Then the active-adjust of the thermal management system can be easily realized.

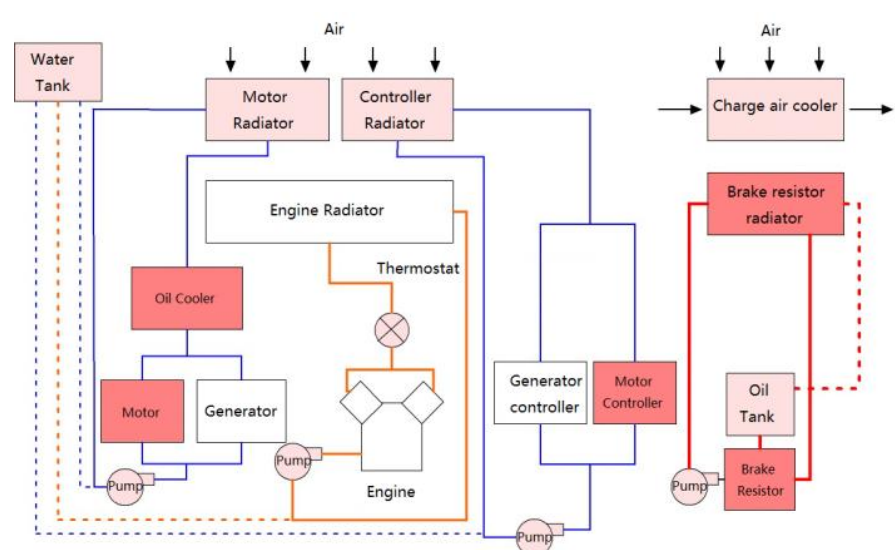

Figure 4. The schematic of the thermal management system with electric consuming system in electric consuming brake process.

In the brake process, when the voltage and SOC of the battery reach to their maximum limitations, the vehicle works in its electric consuming brake mode. In this situation, integrated brake system opens the operating switch to active the brake resistor. Then the brake resistor starts to be charged. The temperature of the brake resistor begins to go up. And then the electric consuming brake cooling system goes to work as the temperature going up. Before this process, the bus voltage of the vehicle should be checked firstly. Then the signal is sent to the integrated controller of the vehicle through the voltage transducer. Compared to the estimated voltage maximum limitation, the integrator unit of the integrated controller should plus one continuously when the measured voltage value is bigger than the calculation value. When the accumulative value exceeds the set value, the brake resistor is active.

\subsection{Power Delivery and Pattern Recognition of Electric Brake}

The power delivery of the series-parallel hybrid electric vehicle studied in this paper under electric brake condition is shown in Figure 5. Figure 5(a) shows the power delivery in the electric regenerative brake process. Figure 5(b) shows the power delivery in electric consuming brake process. In electric brake condition, when the vehicle is braking, the motor works at generating mode to provide the necessary auxiliary power and to charge the battery pack in order to achieve the recycling of brake energy. Meanwhile, the brake torque can be generated by the motor applying a brake force to the wheels through the transmission. In this process, the engine is idle or stop. The generator is stop. The direction of the power fluid is opposite to the electric driving condition. The heat source components include motor, motor controller and transmission oil. In a high intensity or continuous brake process, considering the limitation of capacity of batteries and the other energy storage component, the recycled energy can not be completely absorbed. In this situation, brake resistor needs to be used to consume the excess energy generated from the brake process in order to ensure the safety and reliability of the vehicle.

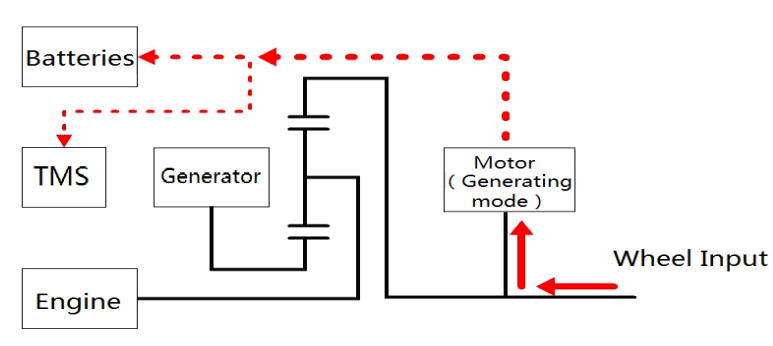

(a)The power dilivery in electric regenerative brake process(TMS:thermal management system)

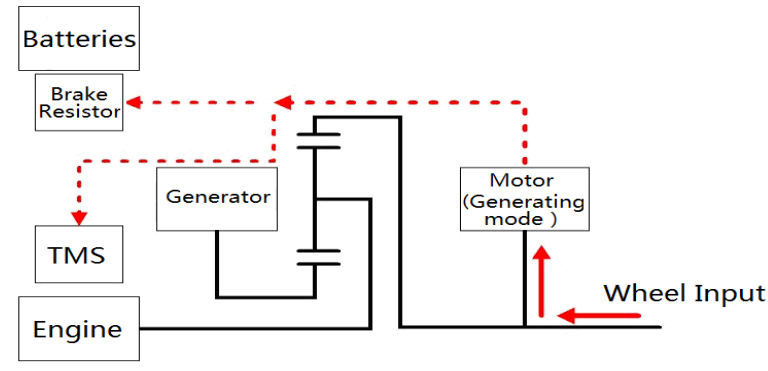

(b)The power dilivery in electric energy consuming brake process(TMS:thermal management system)

Figure 5. The power dilivery in electric brake process of seriesparallel hybrid electric vehicle

Depending on different brake decelerations, the brake process of series-parallel HEV can be divided into three cases: the emergency brake, moderate brake, and mild brake (such as long downhill brake and continuous brake). The socalled emergency brake is the brake process in which brake deceleration is greater than $3 \mathrm{~m} / \mathrm{s} 2$. Under this situation, if the vehicle battery is fully charged, it should enable the electric consuming brake system in order to ensure the safety and reliability of the vehicle. Refers to the moderate brake, it is a normal brake process in which the brake deceleration is in the range of $1 \mathrm{~m} / \mathrm{s} 2$ to $3 \mathrm{~m} / \mathrm{s} 2$. In this situation, the electric regenerative brake could be completely applied. Mild brake is a kind of brake in which the brake deceleration is smaller than $1 \mathrm{~m} / \mathrm{s} 2$. The brake process usually occurs under certain conditions, such as 
long downhill condition of the vehicle, etc. In this case the battery charging time of the HEV is relatively long. The charging characteristics of the battery pack have great influence on the recycling capacity of vehicle electric brake. Under this circumstance, the energy consuming heat dissipation system should be enabled by detecting the battery SOC in order to ensure the safety of the vehicle.

\subsection{Calculation of the vehicle brake process}

In the vehicle brake process, the motor works in its generating mode. The kinetic of the vehicle is transferred to the electricity which is used to charge the battery in order to realize the energy recycling. Under this circumstance, the brake force generated by the motor can be calculated by the following formula.

$$
F_{b m}=i_{g} i_{0} \tau_{b m} \eta_{m} \eta_{t} / r_{w}
$$

$F_{b m}$ is the brake force of the motor, $\tau_{b m}$ is the brake torque of the motor, $i_{g}$ is the ratio of the transmission, $i_{0}$ is the ratio of the side reducer, $\eta_{m}$ is efficiency of the motor, $\eta_{t}$ is the efficiency of the transmission, $r_{w}$ is the wheel radius.

According to the following classic driving equation, the energy consumed in the driving or brake process can be calculated.

$$
E=\int P_{v} d t=\int F_{r} v d t
$$

$E$ is the energy consumed in the vehicle driving or brake process, $P_{v}$ is the power consumed in the vehicle driving or brake process, $F_{r}$ is the force required in the vehicle driving or brake process, $v$ is velocity of the vehicle.

$$
\begin{aligned}
& F_{b r}=\delta M \frac{d v}{d t}+F_{f}+F_{w}+F_{i} \\
& =\delta M \frac{d v}{d t}+M g f \cos \theta+\frac{1}{2} \rho_{a} C_{D} A v^{2}+M g \sin \theta
\end{aligned}
$$

$F_{b r}$ is the required brake force of the whole vehicle, $\delta$ is the equivalent mass of rotating parts, $M$ is the mass of the whole vehicle, $F_{f}$ is the rolling resistance, $F_{w}$ is the aerodynamic resistance, $F_{i}$ is the gradient resistance, $g$ is the gravitational acceleration, $f$ is the rolling resistance coefficient, $\theta$ is the slope of road, $\rho_{a}$ is the density of air, $C_{D}$ is the air drag coefficient, $A$ is the frontal area of vehicle.

\subsection{Control strategy of electrical brake}

According to the relative parameters of the seriesparallel hybrid electric vehicle, we can acquire the maximum motor brake force and the maximum brake intensity of motor in its independent brake process. The motor could take part in brake all the time during the vehicle operation, because of the electric consuming brake system.
When the initial vehicle brake velocity is in a certain speed range, the electrical brake can be used as its maximum brake intensity which the motor permits. When the brake velocity is smaller than some minimum velocity, the motor can't join in the brake process because of the enormous damping of the electrical brake intensity. Under this circumstance, the mechanical brake work as prime brake.

When the motor brake force can't fulfill the requirement that the vehicle actually needed, the electrical-mechanical combined brake need to be applied. On one side, the electrical brake motor is allowed to work with its maximum brake intensity. On the other side, the mechanical brake supplies the additional portion of the brake force needing to fulfil the totally brake pedal stroke. When the vehicle speed falls below a certain speed, the electrical brake can't fulfil the basic work, due to damping of the intensity of electrical brake. Under this circumstance, the mechanical brake plays the major role to meet the brake strength requirement of brake pedal stroke. The maximum vehicle brake force is not only related to the brake vehicle velocity, but also limited by the mechanical brake device and the total brake power of the motor.

The specific electrical brake strategy can be achieved as following.

1) Enter the battery SOC, the vehicle velocity, the deceleration motor characteristics and battery characteristics.

2) Judge SOC and velocity, when velocity exceeds the minimum velocity, the electrical brake is active. Otherwise mechanical brake is applied. In the electrical brake process, when the SOC of the battery exceeds 0.8 , electric consuming brake is active. The surplus electricity is input to the brake resistor, or else goes to the next step.

3) Calculate the maximum battery charging powers which are separately limited by the maximum voltage and maximum current of the battery.

4) Calculate the maximum brake force which the motor can provide and the required brake force of wheels by the vehicle velocity and the brake deceleration. When the maximum brake force which the motor can provide is bigger than the required brake force of wheels, vehicle brake force can be provided entirely by the motor. In this situation, the vehicle brake force is equal to the required brake force of wheels. Then calculate the motor recovery power under the circumstance. When the maximum brake force which the motor can provide is smaller than the required brake force of wheels, the electrical-mechanical combined brake should be applied in order to maintain the stability of the vehicle deceleration. In this situation, the motor provides its maximum brake force and the rest of the brake force provided by the mechanical brake. The vehicle brake force is equal to the sum of mechanical brake force and electrical brake force. Then calculate the recovery power of motor.

5) Compare the recovery power of motor with the maximum charging power the battery permitted. When the recovery power of motor is smaller than the maximum charging power the battery permitted, the electricity can be charged into 
battery. Or else, the recovered energy needs to be charged into the brake resistor.

\section{Simulation Model}

According to the vehicle structure and working condition and process analysis, a mechanical-electricalthermal coupled model of a series-parallel hybrid electric vehicle combined with powertrain model and thermal management system model is proposed. Using this coupled model, global and predictive power delivery, distribution and dynamic heat characteristics of components in the different driving condition especially for the complex brake process can be studied.

\subsection{The schematic of the series-parallel hybrid electric vehicle}

The schematic of the series-parallel hybrid electric vehicle is illustrated in Figure 6. The hybrid power system of series-parallel hybrid electric vehicle includes the internal combustion engine, the motor $\mathrm{A}$, the motor $\mathrm{B}$, the planetary power coupling device and so on. The internal combustion engine is linked to the planet carrier, the motor $\mathrm{A}$ is linked to the sun gear, and the motor B is linked to the ring which is paralleled on the output shaft. Both the motor A and the motor B can operate as generators or driving motors. In the series-parallel hybrid electric vehicle, the engine power is split by the planetary power coupling device. Some of the engine power is transmitted to the output shaft as mechanical power. Some of the engine power is transmitted by the motor A to the motor B or battery as electrical power. The torques of the motor B and the planet ring are coupled on the output shaft, and power split and coupling are implemented by the planetary power coupling device.

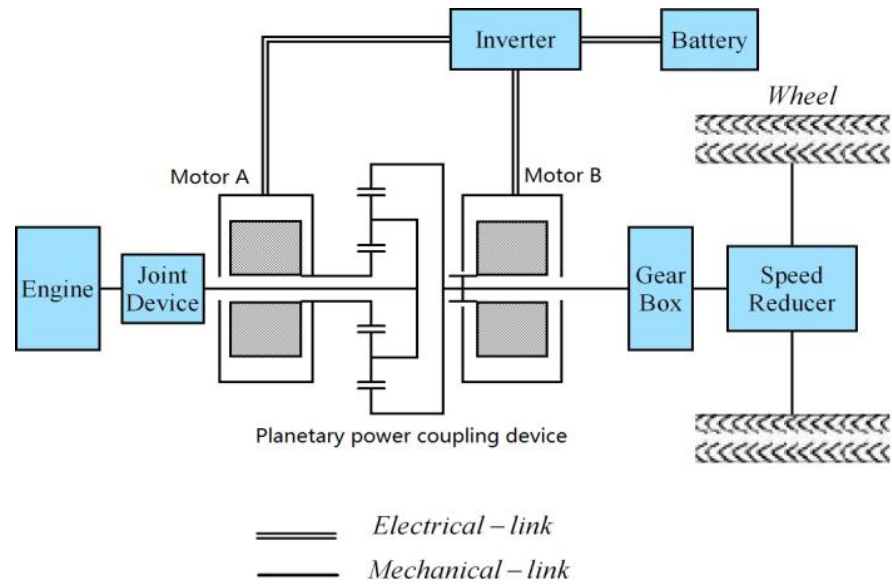

Figure 6. Schematic of series-parallel hybrid electric vehicle with planetary power coupling device.

\subsection{The simulation model of the whole vehicle}

Based on the unique vehicle structure and schematic, a coupled vehicle model which combined the driveline model and the thermal management system model is applied in the study. The hybrid modeling method which combines experiment modeling and theory modeling is adopted. The vehicle forward dynamic driveline simulation model is built with MATLAB/Simulink which is shown in Figure 7. The thermal management system model which contains dynamic dissipation calculation model, temperature rising calculation model and the control strategy are also built in details with MATLAB/Simulink, which is shown partly in Figure 8. The thermal management system contains the electric consuming brake cooling subsystem which is related to the vehicle electric consuming brake process. According to the coupled model, the energy flow, energy distribution and heat characteristics of components under different driving condition can be studied in details, especially for the brake energy flow and storage in the brake process. The effectiveness of the unique brake system and brake control strategy can be estimated by the simulation.

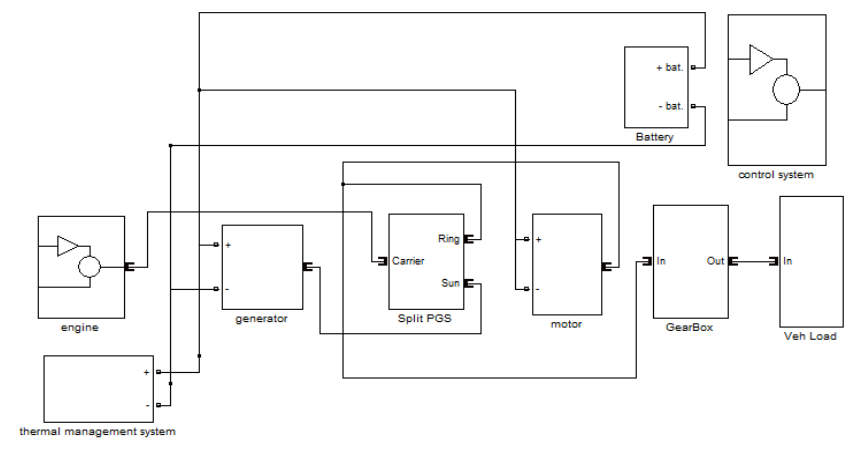

Figure 7. The dynamic simulation model of the whole vehicle

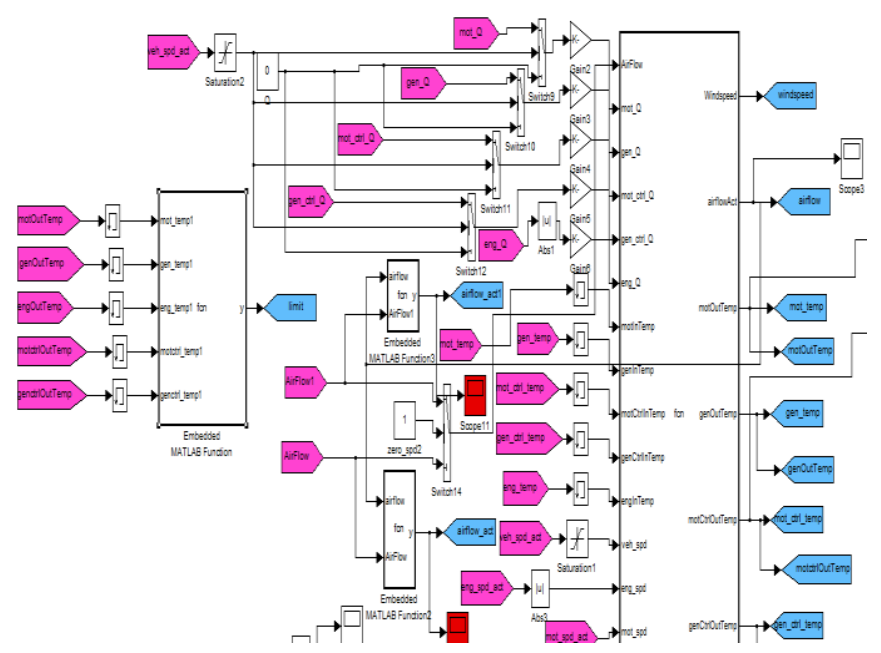

Figure 8. Part of the thermal management system model

\section{Analysis Of Simulation Results}

In different vehicle driving conditions, the ratio of brake energy and total energy is different. In the simulation, an international general urban road driving cycle UDDS is applied. As shown in Figure 9, the maximum velocity is 91.2 
$\mathrm{km} / \mathrm{h}$. The initial SOC of the battery is set to 0.7 . The simulation results can be seen in Figure 10 to Figure 12.

According to the UDDS driving cycle, the vehicle needs to start, stop, accelerate and brake frequently. The SOC of the battery always declines. In light of recycling energy of the electrical brake, the SOC changing curve goes up and down accordingly which is related to the charge-andrecharge process. During the driving cycle, the specific changing process of battery SOC is shown in Figure 10. In the driving cycle, the vary process of bus voltage can be seen in Figure 11.

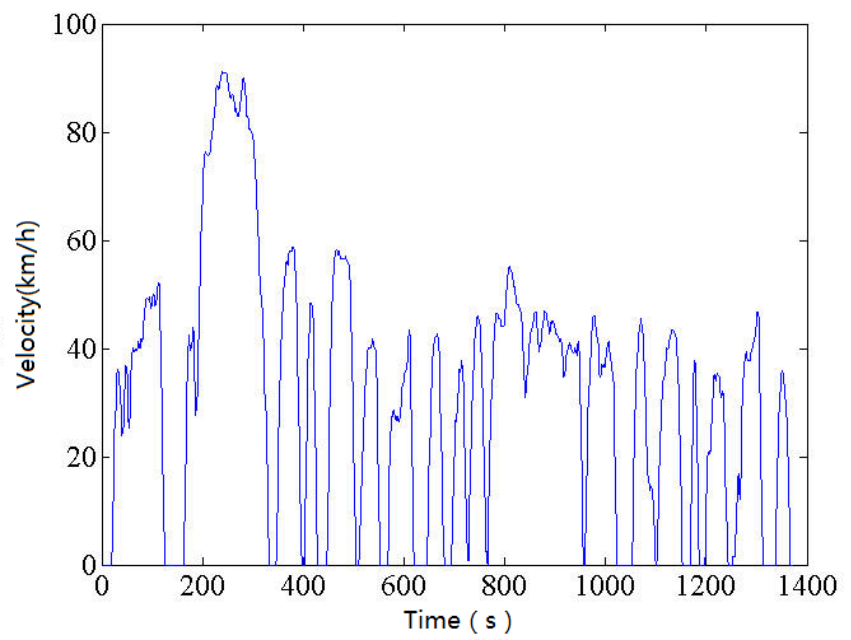

Figure 9. UDDS driving cycle.

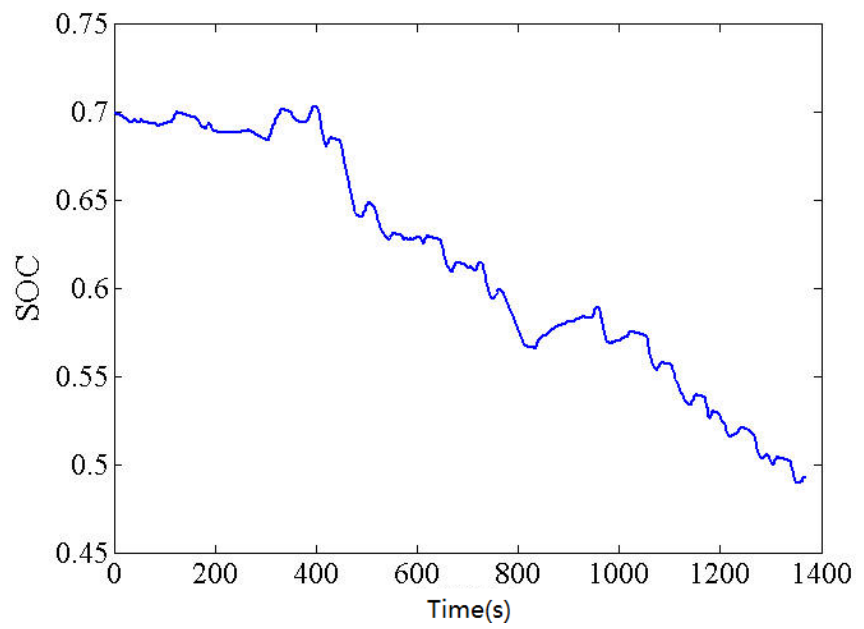

Figure 10 . The SOC of the battery changing process in the UDDS driving cycle.

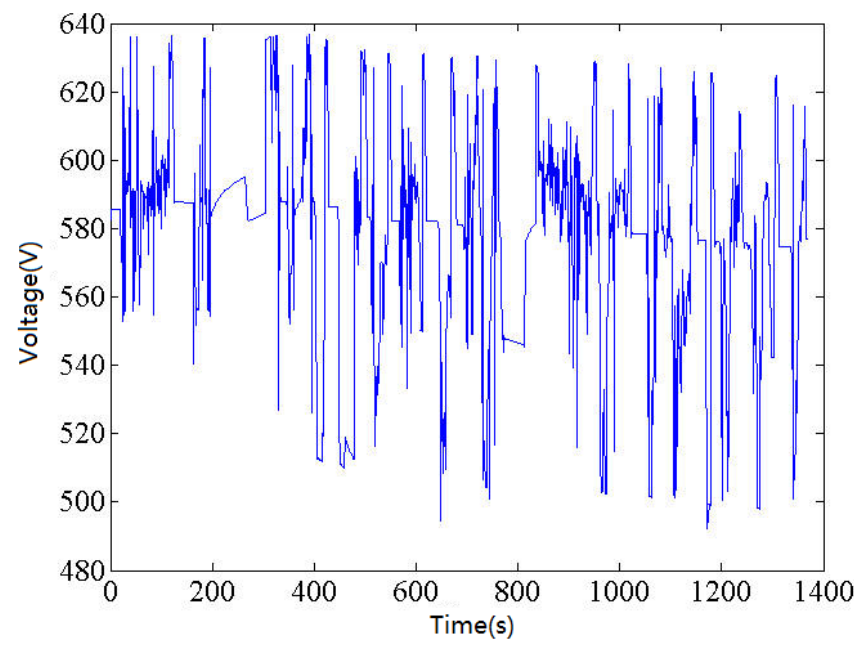

Figure 11. The bus voltage changing process in the UDDS driving cycle.

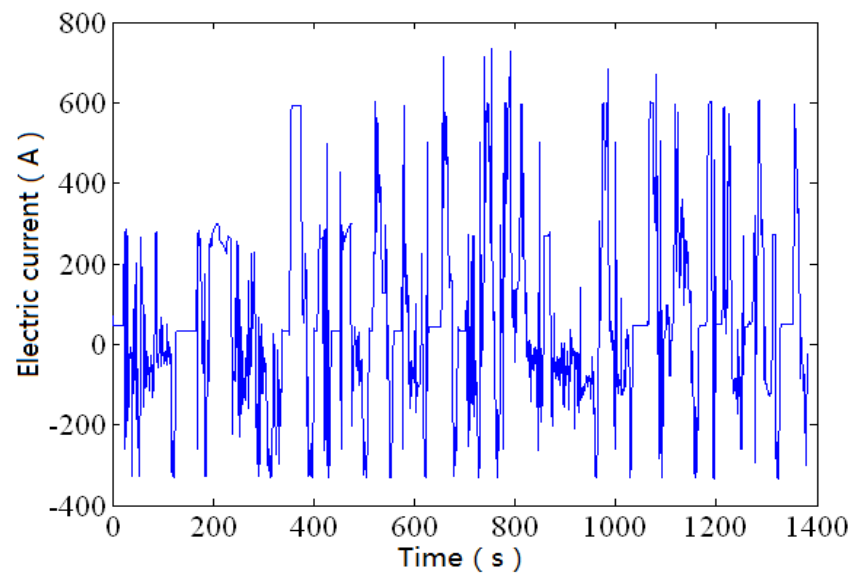

Figure 12. The bus current changing process in the UDDS driving cycle.

The changing process of bus current in the whole driving cycle is shown in Figure 12. The research results show that when the bus voltage is lower than current SOC corresponding voltage limit value, the bus current is always less than the corresponding current limit value. In view of the results, the bus voltage is set as the key control parameter to active the switching of different kinds of brake in the brake process. When the bus voltage value exceeds detection limit voltage, the electric consuming brake is activated. Under the circumstance, the energy generating from the motor is transferred to the brake resistor. In the simulation, the limitation value of the bus voltage is set to $620 \mathrm{~V}$.

There are four kinds of energy can be referred to study the energy flow of series-parallel hybrid electric vehicle in the UDDS driving cycle. They are vehicle driving energy, vehicle brake energy, vehicle brake recycle energy which is related to the electrical brake process and vehicle effective brake recycle energy. According the simulation, throughout the driving cycle, the drive energy of the vehicle is $76030.2 \mathrm{KJ}$. The vehicle brake energy during all the brake 
processes is $36823.3 \mathrm{KJ}$. In the whole driving cycle, the brake energy takes up $32.6 \%$ of the total energy consumption. In the most of the brake process, the electrical brake can be applied.

The brake recycle energy takes up nearly $70 \%$ of the total brake energy, while the effective brake recycle energy takes up $26.3 \%$ of the total brake energy. Base on this analysis results, the electrical brake system is applied in most of the brake process. In the whole driving cycle, the recycle brake energy used to charge the battery takes up nearly one third of the total brake energy. While the other two thirds recycle brake energy is transferred to the electric consuming brake system which can be used to warm-up the engine, heat the cab and seat of the series-parallel hybrid electric vehicle in order to realize the maximum utilization of the vehicle energy.

This function of electric consuming brake which turns the electricity into heat is very useful for some kinds of vehicle working condition under low ambient temperature, especially for the usage in the high altitude condition. In high altitude areas, the temperature is very low. The air pressure is also very low. Under this circumstance, heating needs to be used widely in the engine cold start, transmission cold start, battery warm-up and cab environment heating. Later on, the more specific and detailed control strategies of the whole vehicle integrated system management aiming at both greater energy saving and better man-machine comfort performance need to be developed.

Simulation results show that the complex integrated brake system and control strategy are effective for the seriesparallel hybrid electric vehicle. It not only can ensure the security of the vehicle driving and battery energy storage, but also can enhance the energy utilization and prolong the working lifetime of mechanical brake device in the brake process.

\section{Conclusion}

The complex integrated brake system with electric consuming brake subsystem and advanced strategy proposed in this paper can fulfill the various brake requirement of the series-parallel hybrid electric vehicle under different driving conditions. In view of the complexity and dynamic characteristics of the different brake conditions, an integrated simulation analysis method based on a coupled vehicle model which combined the driveline model and the thermal management system model is proposed to study the energy flow and utilization of the electrical brake. According to the simulation results under the UDDS driving cycle, the analysis method based on the coupled simulation model can be applied on the dynamic brake traits and energy distribution research for series-parallel hybrid electric vehicle feasibly and effectively.

\section{Acknowledgment}

Fanatical and technical supports from the Chinese State Scholarship fund and China North Vehicle Research Institute are gratefully acknowledged.

\section{References}

[1] Kanarachos S, Alirezaei M, Jansen S, Maurice J. "Control allocation for regenerative brake of electric vehicles with an electric motor at the front axle using the state-dependent Riccati equation control technique". Proc Inst Mech Eng D J Automot Eng 2014;228:129-43.

[2] J. Ko, S. Ko, I. Kim, D. Hyun, and H. Kim, "Co-operative control for regenerative brake and friction brake to increase energy recovery without wheel lock," Int. J. Autom. Technol., vol. 15, no. 2, pp. 253-262, Mar. 2014.

[3] Jo C, Ko J, Yeo T et al. Cooperative regenerative brake control algorithm for an automatic-transmissionbased hybrid electric vehicle during a downshift. Proc IMechE Part D: J Automobile Engineering 2012; 226(4): 457-466.

[4] Xu G, Li W, Xu K, Song Z. An intelligent regenerative brake strategy for electric vehicles. Energies 2011;4:1461-77.

[5] O. Bottauscio,M. Chiampi, and A.Manzin, "Modeling analysis of the electromagnetic brake action on rotating solid cylinders," Applied Mathematical Modelling, vol. 32, no. 1, pp. 12-27,2008.

[6] Quan Zhou, Xuexun Guo, Gangfeng Tan, Xiaomeng Shen, Yifan Ye, and Zhaohua Wang, "Parameter Analysis on Torque Stabilization for the Eddy Current Brake: A Developed Model, Simulation, and Sensitive Analysis," Mathematical Problems in Engineering, vol. 2015, pp. 1-10, 2015.

[7] Ren He, and Donghai Hu, "Nonlinear Coupling Characteristics Analysis of Integrated System of Electromagnetic Brake and Frictional Brake of Car," Mathematical Problems in Engineering, vol. 2015, pp. 1-14, 2015. 